\title{
Oscillatory Behavior in Cobalt Electrodeposition with 3-Mercapto-1-Propanesulfonate
}

\section{Supporting Information}

\author{
Y. Hu, Q. Huang ${ }^{z}$
}

Department of Chemical and Biological Engineering, University of Alabama, Tuscaloosa, AL

\section{z:qhuang@eng.ua.edu}
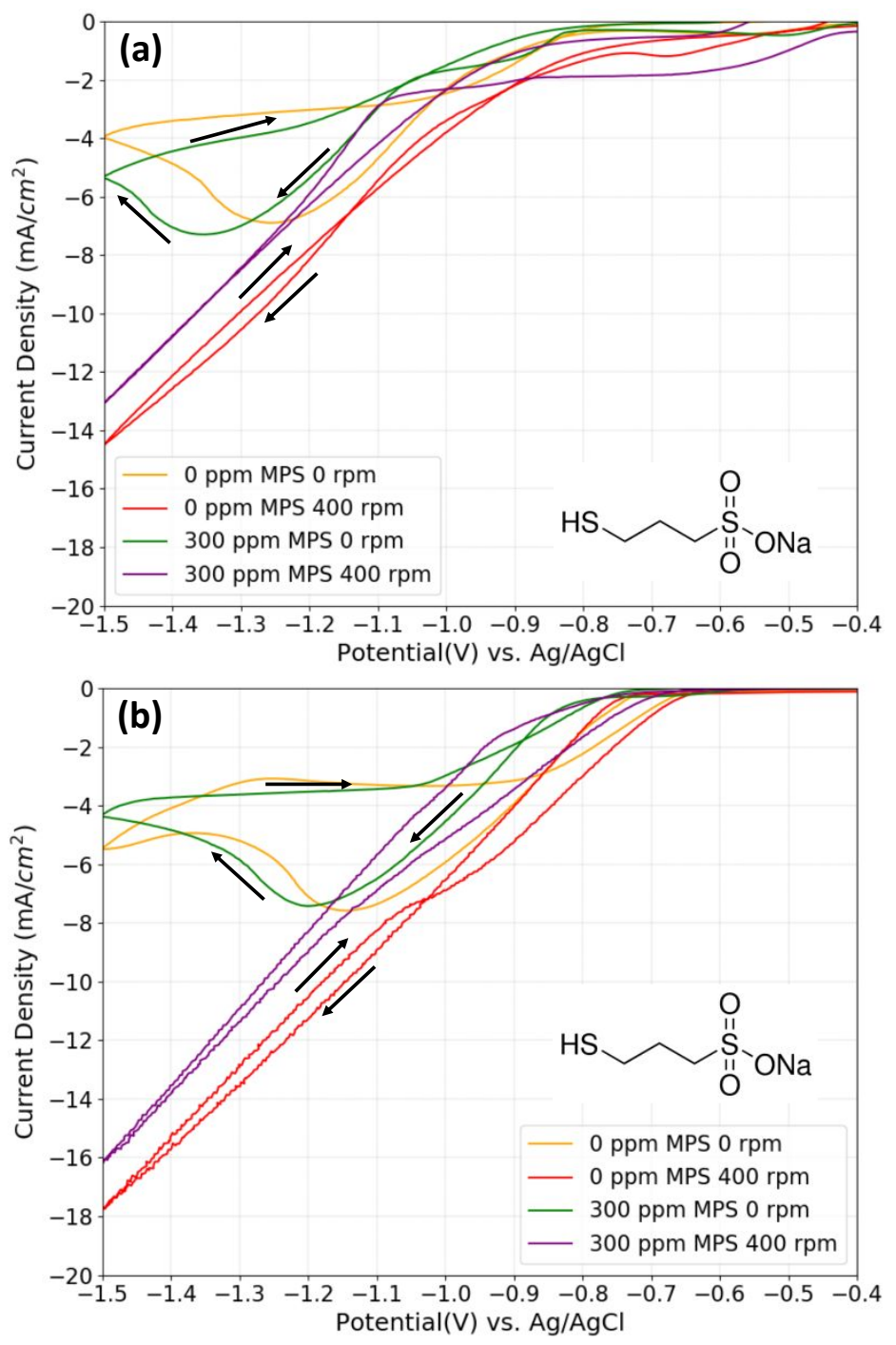

Figure S1. Cyclic voltammetry of Co electrodeposition on Pt RDE at different rotation rates in $0.05 \mathrm{M}$ Co solutions with different MPS concentrations at (a) $\mathrm{pH}=3$, (b) $\mathrm{pH}=5$.67. Scan rate $=20 \mathrm{mV} / \mathrm{s}$ 


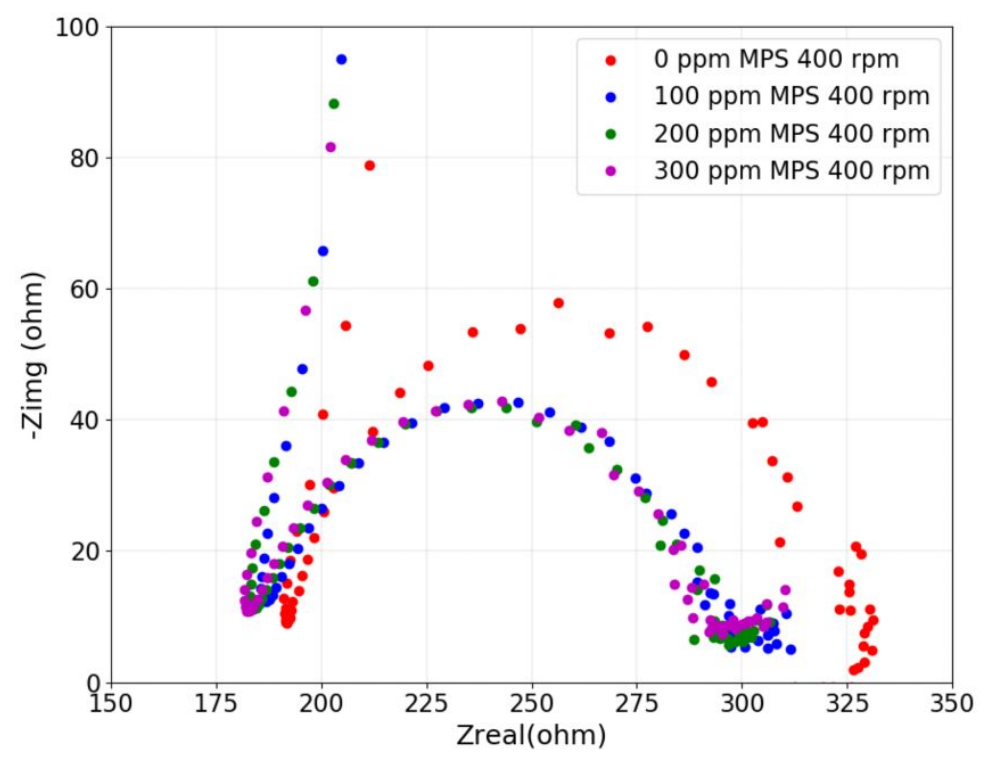

Figure S2. Electrochemical impedance spectra of Co deposition in $0.05 \mathrm{M}$ Co solutions with different MPS concentrations at $\mathrm{pH}=3$. The rotation rate was $400 \mathrm{rpm}$ and the applied current density was $-2.55 \mathrm{~mA} / \mathrm{cm}^{2}$. The resistance of solution was high and similar regardless of the addition of MPS.

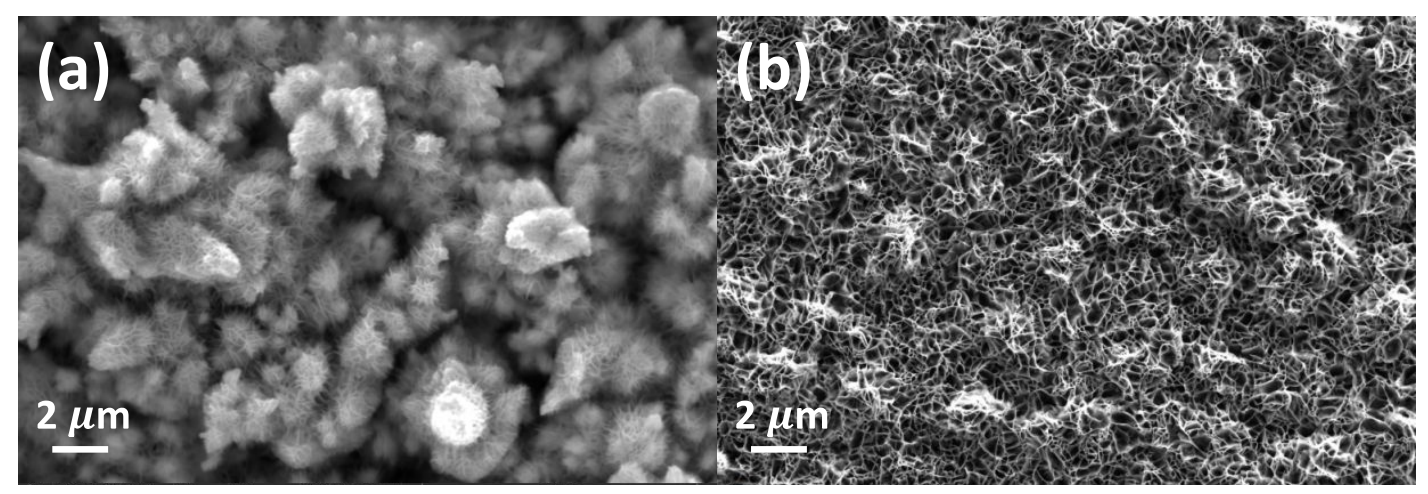

Figure S3. Top down SEM micrographs of the surface morphology of cobalt films deposited at $-5.10 \mathrm{~mA} / \mathrm{cm}^{2}$ and $400 \mathrm{rpm}$ in $0.05 \mathrm{M}$ Co electrolyte at $\mathrm{pH}=5.67$ with (a) $0 \mathrm{ppm}$ MPS with no oscillation observed, and (b) 300 ppm MPS, where oscillation was observed. 


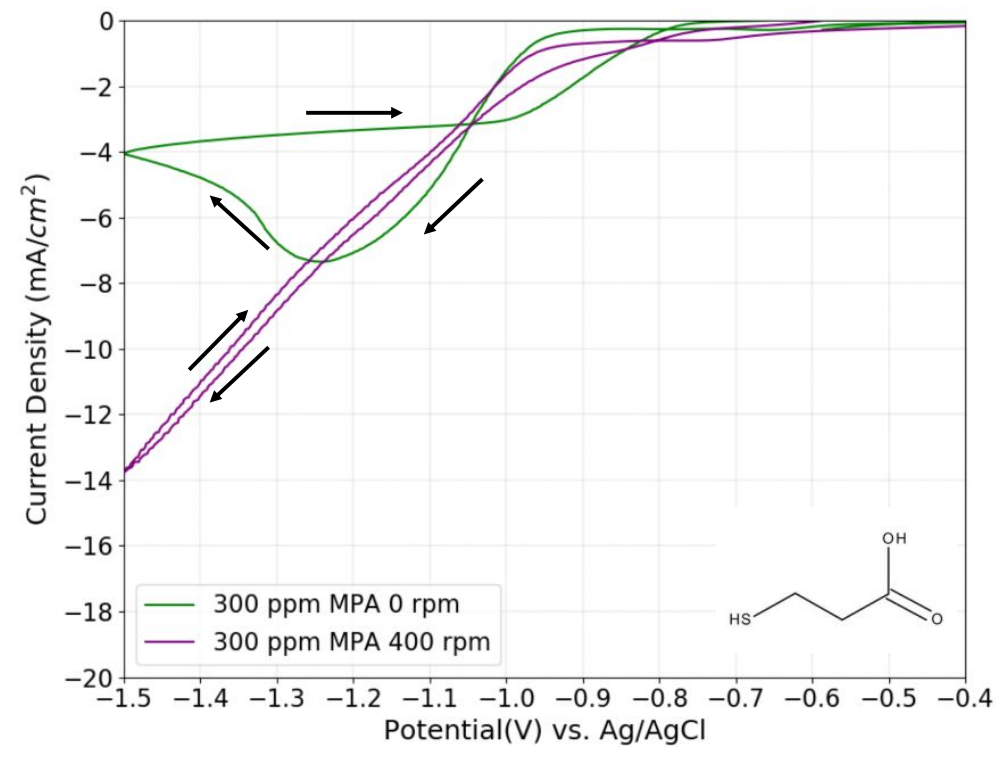

Figure S4. Cyclic voltammetry of Co electrodeposition on Pt RDE at different rotation rates in $0.05 \mathrm{M}$ Co solutions with $300 \mathrm{ppm}$ MPA concentrations at adjusted $\mathrm{pH}=5.67$. Scan rate $=$ $20 \mathrm{mV} / \mathrm{s}$. 